\title{
Pesquisas sobre a formação matemática de professores para os anos iniciais do ensino fundamental
}

\author{
Researches about the formation of mathematics teachers \\ for the early years of elementary school
}

\author{
Investigación sobre la formación matemática de los maestros \\ para los primeros años de la escuela primária
}

\author{
MARIA LÍDIA SICA SZYMANSKI* \\ JOSIANE BERNINI JORENTE MARTINS**
}

\begin{abstract}
RESUMO
O presente artigo objetiva responder à questão: "O que revelam as pesquisas sobre a formação matemática dos professores dos anos iniciais do ensino fundamental?". Com esse intuito, realizou-se uma pesquisa bibliográfica na Biblioteca Digital de Teses e Dissertações - BDTD, no período de 2004 a 2014. Utilizou-se a Análise de Conteúdo (Bardin) para examinar títulos, palavras-chave, resumos, objetos de estudo, procedimentos metodológicos e resultados. As pesquisas apontam lacunas na formação matemática desses professores. Além de políticas públicas que amparem os processos de formação inicial e continuada, recomendam-se aquelas que promovam a aprendizagem na educação básica, contribuindo para que os alunos cheguem à universidade com os conhecimentos matemáticos fundamentais.
\end{abstract}

Palavas-chave: Formação de professores. Educação matemática. Ensino fundamental.

\begin{abstract}
This article aims to answer the question: "What is revealed in educational researches, addressing the mathematical formation of teachers who work in the early years of elementary school?". To that end, a research was conducted in the Digital Library of Theses and Dissertations - BDTD, from 2004 to 2014. Based on Content Analysis (Bardin), were examined bonds, keywords, summaries, objects of study, methodological procedures and results. Research indicates that the early years' teachers have gaps in their mathematical formation. Besides public policies supporting Initial and continuing education, we recommend public policies promoting learning in basic education, helping students to come to the university with the fundamental mathematical knowledge.
\end{abstract}

Keywords: Teachers formation. Mathematics education. Elementary school.

\section{RESUMEN}

Este artículo tiene como objetivo responder la pregunta: “¿Lo que se revela en la investigación educativa, dirigiéndose a la formación matemática de los maestros que trabajan en los primeros años de la escuela primaria?". Con el fin de responder a esta pregunta, se realizó una búsqueda bibliográfica en la Biblioteca Digital de Tesis y Disertaciones - BDTD, de 2004 a 2014. Se utilizó el análisis de contenido (Bardin) para examinar los títulos, palabras clave, resúmenes, materia, procedimientos metodológicos y resultados. Las investigaciones indican lagunas en la formación matemática de estos maestros. Además de las políticas públicas que amparen se recomiendan los procesos de formación inicial y continua que promueven el aprendizaje en la educación básica, y ayuden a los estudiantes llegar a la universidad con el conocimiento matemático fundamental.

Palabras clave: Educación matemática. Formación del profesorado. Enseñanza primaria.

\footnotetext{
* Doutora em Psicologia pelo IP/USP. Pós-Doutora em Psicologia, Desenvolvimento Humano e Educação, pelo Departamento de Psicologia da FE/UNICAMP. Docente do Mestrado em Educação da UNIOESTE.E-mail: <szymanski@hotmail.com>.

** Mestre em Educação pela Universidade Estadual do Oeste do Paraná - UNIOESTE. Professora da Educação Básica da rede estadual de educação do Estado do Paraná. E-mail: <josianejorente@hotmail.com>.
} 


\section{INTRODUÇÃO}

A preocupação com a formação inicial dos professores para atuarem nos anos iniciais do ensino fundamental tem provocado discussões significativas entre educadores e pesquisadores, favorecendo o aumento de pesquisas realizadas sobre o tema. Este texto objetiva discuti-lo, entendendo como processos formativos formais o curso de Formação de Docentes da Educação Infantil e dos Anos Iniciais do Ensino Fundamental na modalidade normal, em nível médio ${ }^{1}$, e o curso de Pedagogia.

Segundo a legislação vigente, a formação inicial desse professor deve ocorrer no curso de Pedagogia, que proporciona uma polivalência funcional. As Diretrizes Curriculares Nacionais (2006) para o Curso de Pedagogia, licenciatura, estabelecem que essa formação inicial prepare para o exercício da docência na educação infantil e nos anos iniciais do ensino fundamental, nos cursos de Ensino Médio, na modalidade normal, e em cursos de Educação Profissional, na área de serviços e apoio escolar, bem como em outras áreas nas quais sejam previstos conhecimentos pedagógicos.

O professor pedagogo que assume a docência nos anos iniciais do ensino fundamental precisa - além de planejar as aulas e escolher as formas de avaliação - conhecer os conceitos científicos e dominar os procedimentos metodológicos para o ensino das diversas disciplinas, entre as quais está a Matemática. De acordo com as pesquisas realizadas por Nacarato, Mengali, Passos (2009), Marmitt (2009), Frota (2003) e Silveira (2002), muitos desses professores e futuros professores dos anos iniciais não gostam da Matemática, disciplina sobre a qual trazem concepções negativas. Entretanto, durante a formação inicial específica para a docência, essas concepções e sentimentos constituídos a partir da história de vida de cada pessoa podem ser tanto reforçados quanto mudados (CURI, 2000; ZAT, 2012).

Várias pesquisas sobre a formação inicial e continuada têm-se desenvolvido devido à relevância do tema para a atuação de professores. Assim, na busca de melhoria na qualidade dos processos de ensino e de aprendizagem nos anos iniciais, este texto objetiva apresentar o que se revela nas pesquisas em educação que abordam a formação matemática dos professores que atuam nos anos iniciais do ensino fundamental.

Nessa perspectiva, optou-se em direcionar a investigação para os trabalhos stricto sensu, disponíveis na Biblioteca Digital de Teses e Dissertações - BDTD, no período de 2004 a $2014^{2}$. Os trabalhos foram

\footnotetext{
${ }^{1}$ O curso Formação de Docentes da Educação Infantil e dos Anos Iniciais do Ensino Fundamental, na modalidade normal, em nível médio, é denominado neste texto como Formação de Docentes em nível médio.

2 Disponível em: <http://bdtd.ibict.br/>. Acesso em: fev. 2015.
}

categorizados e analisados buscando-se compreender possíveis dificuldades e desafios relacionados à formação docente para os anos iniciais.

Além da introdução, este artigo estrutura-se em duas seções. Na primeira, apresenta-se um breve relato das leis que orientam a formação e a função docente nos anos iniciais. Ainda na perspectiva da pedagogia histórico-crítica, destaca-se a importância da apropriação do conhecimento científico para o exercício da docência e para a aprendizagem discente. Finaliza-se apresentando uma síntese dos assuntos abordados nas pesquisas referentes à educação matemática nos anos iniciais.

Para a segunda seção, dentre os 57 trabalhos apontados na seção 1 , selecionam-se e analisam-se aqueles voltados à formação para a docência matemática nos anos iniciais do ensino fundamental. Com base na Análise de Conteúdo (BARDIN, 2011), foram examinados títulos, palavraschave e resumos. Ainda buscou-se identificar o objeto de estudo, os procedimentos metodológicos e os resultados obtidos.

Tecem-se, a seguir, as considerações "não finais" no sentido de que muito ainda há a se caminhar com relação à formação docente para os anos iniciais. Sintetizam-se as discussões reveladas pelas pesquisas analisadas e apontase a relevância de políticas públicas que contribuam para o avanço na qualidade da atuação do trabalho pedagógico relativo à educação Matemática nos anos iniciais.

\section{ENSINO DE MATEMÁTICA NOS ANOS INICIAIS}

Embora o número de pesquisas relacionadas ao ensino e à aprendizagem de Matemática nos anos iniciais, assim como à formação do professor que ensina essa disciplina, revele avanços, há ainda muitas questões necessitando de estudos que contribuam para a ampliação das discussões sobre o tema (NACARATO; MENGALI; PASSOS, 2012).

Por um lado, $[. .$.$] constatamos que eventos científicos$ tradicionais da Educação Matemática, como o Encontro Nacional de Educação Matemática (ENEM), o Simpósio Internacional de Pesquisa em Educação Matemática (SISPEM), a Conferência Interamericana de Educação Matemática (CIAEM), entre outros, vêm organizando grupos de trabalho específicos voltados aos anos iniciais. Por outro lado, as produções ainda são escassas, e compreendemos que muitas questões em relação ao processo de ensino e aprendizagem, além da formação dos professores que ensinam Matemática nos anos iniciais do Ensino Fundamental, merecem maior atenção por parte dos pesquisadores (LOPES et al., 2012). 
Essa necessidade também se justifica pelas mudanças que têm ocorrido nos anos iniciais da educação básica e na formação inicial do docente para atuar nesse nível de ensino. "Entre as mudanças recentes mais significativas, atenção especial passou a ser dada à ampliação do ensino fundamental para nove anos de duração, mediante a matrícula obrigatória de crianças com 6 (seis) anos de idade, objeto da Lei no 11.274/2006" (BRASIL, 2013, p. 103).

Outra importante mudança refere-se ao nível da formação inicial de professores para atuar na educação infantil e nos anos iniciais do ensino fundamental. Durante muito tempo, essa formação foi de responsabilidade dos cursos normais em nível médio (Magistério), mas, de acordo com o artigo 62 da Lei de Diretrizes e Bases da Educação Nacional - LDBEN 9394/96, passou a ser responsabilidade também do ensino superior.

Art. 62. A formação de docentes para atuar na educação básica far-se-á em nível superior, em curso de licenciatura, de graduação plena, em universidades e institutos superiores de educação, admitida, como formação mínima para o exercício do magistério na educação infantil e nas quatro primeiras séries do ensino fundamental, a oferecida em nível médio, na modalidade Normal (BRASIL, 2006).

Observa-se que esse artigo, embora proponha que a formação do professor da educação básica (educação infantil, ensino fundamental e ensino médio) ocorra em nível superior, ao mesmo tempo aceita como formação mínima para a docência na educação infantil e nos anos iniciais do ensino fundamental o nível médio na modalidade normal.

Ainda na perspectiva da formação docente, a Resolução $\mathrm{CNE} / \mathrm{CP}^{3} \mathrm{n}^{\mathrm{0}}$ 1/2002, de 18 de fevereiro de 2002, instituiu as Diretrizes Curriculares Nacionais para a Formação de Professores da Educação Básica, em nível superior, curso de licenciatura, de graduação plena. A partir dessa resolução, os cursos de Pedagogia e Normal Superior passaram a ser os principais responsáveis pela formação, em nível superior, de professores para os primeiros anos da educação básica.

Com a Resolução no 1 , de 15 de maio de 2006 - CNE/ $\mathrm{CP}$, que instituiu as Diretrizes Curriculares Nacionais para o Curso de Graduação em Pedagogia, licenciatura, os cursos de Pedagogia já existentes e o curso Normal Superior foram extintos, transformados ou reestruturados. Assim, nos estados brasileiros, a formação de professores para os anos iniciais do ensino fundamental acontece, conforme preconiza a LDBEN, preferencialmente, ainda

\footnotetext{
${ }^{3}$ Conselho Nacional de Educação/Conselho Pleno.
}

que não exclusivamente, por meio do curso de Pedagogia readequado à resolução vigente.

Atualmente, a Resolução no. 02/2015, de 9 de junho de 2015, embora tenha revogado a Resolução no $1 / 2002$, não alterou os itens aqui ressaltados. No estado do Paraná, de modo geral, os professores que atuam nos anos iniciais têm como formação inicial à docência o curso de Pedagogia, que habilita para atuar na educação infantil e anos iniciais do ensino fundamental, ou o curso de Formação de Docentes, em nível médio, na modalidade normal (Magistério).

No tocante à função do professor, tendo em vista os objetivos do ensino fundamental, a LDBEN 9394/96, em seu artigo 13, traz como sua incumbência zelar pela aprendizagem dos alunos, e o artigo 32 apresenta como objetivo do ensino fundamental a formação básica do cidadão mediante:

I - o desenvolvimento da capacidade de aprender, tendo como meios básicos o pleno domínio da leitura, da escrita e do cálculo; II - a compreensão do ambiente natural e social, do sistema político, da tecnologia, das artes e dos valores em que se fundamenta a sociedade; III - o desenvolvimento da capacidade de aprendizagem, tendo em vista a aquisição de conhecimentos e habilidades e a formação de atitudes e valores; IV o fortalecimento dos vínculos de família, dos laços de solidariedade humana e de tolerância recíproca em que se assenta a vida social (BRASIL, 1996).

Outro ponto importante com relação à formação docente para os anos iniciais diz respeito ao ensino dos conteúdos específicos das disciplinas. A Resolução $\mathrm{n}$ 01/2006 - CNE/CP, em seu artigo 5o, propõe que os professores, egressos do curso de Pedagogia, conheçam as diversas disciplinas a serem ensinadas nos anos iniciais do ensino fundamental, de modo a estabelecerem diálogos entre esses conhecimentos, estando aptos a: [...] VI - ensinar[em] Língua Portuguesa, Matemática, Ciências, História, Geografia, Artes, Educação Física, de forma interdisciplinar e adequada às diferentes fases do desenvolvimento humano [...] (BRASIL, 2006).

Assim, diante do que determina a lei e compreendendo o professor como responsável pelas atividades de mediação nos processos de ensino e de aprendizagem, faz-se necessário que sua formação inicial para a docência nos anos iniciais do ensino fundamental the possibilite a apropriação dos conhecimentos científicos que está autorizado a ensinar.

$\mathrm{Na}$ perspectiva da pedagogia histórico-crítica, a escola é o espaço privilegiado de socialização do saber sistematizado, do conhecimento científico historicamente construído. Essa exigência é que garante a existência da escola “[...] não se trata, pois, de qualquer tipo de saber 
[...] a escola diz respeito ao conhecimento elaborado e não ao conhecimento espontâneo; ao saber sistematizado e não ao saber fragmentado; à cultura erudita e não à cultura popular" (SAVIANI, 2013, p. 14).

No processo de aprendizagem, os alunos humanizam-se, isto é, consolida-se o humano: os conhecimentos científicos, técnicos e artísticos que a humanidade produziu historicamente são apropriados pelo aluno singular, em uma relação dialética entre o singular (o aluno), o particular (suas condições de vida) e o universal (o que o gênero humano produziu em termos de conhecimento científico, técnico e artístico).

Os processos educativos desenvolvidos na escola devem estar embasados na realidade social, proporcionando reflexão e transformação dessa realidade. Como assinala Martins (2013), se o domínio teórico em si não transforma a realidade, dialeticamente não é possível uma prática social transformadora, sem a apropriação das objetivações historicamente produzidas pelos homens. Essa apropriação não apenas lhes possibilita situarem-se e compreenderem as relações de produção na realidade em que se inserem, mas também lhes permite objetivarem-se eles próprios como sujeitos históricos, transformando essa realidade.

A pedagogia histórico-crítica, visando à formação das funções psicológicas superiores, atenção, percepção, memória, linguagem, pensamento, raciocínio entre outras, propõe um ensino orientado para a transmissão dos conhecimentos científicos de forma sistemática (MARTINS, 2013). Ao ensinar, faz-se necessário que o professor desenvolva atividades mediadoras que promovam o aprendizado. Porém, só o fará se tiver domínio dos conhecimentos científicos necessários à docência.

Ora, diante das diferentes formas de permissão legal para o Magistério nos anos iniciais, indaga-se até que ponto a formação desses profissionais - cujo papel social é tão importante, uma vez que são responsáveis por oportunizar às crianças a aprendizagem necessária ao pleno desenvolvimento de suas funções psicológicas superiores - possibilita-lhes a apropriação dos conceitos científicos necessários à atuação pedagógica.

Para responder a essa questão, buscou-se retomar as discussões já realizadas sobre a formação de professores para o ensino da Matemática nos anos iniciais.

\section{ENSINO DE MATEMÁTICA NOS ANOS INICIAIS E AS PESQUISAS: PRIMEIRAS APROXIMAÇÕES}

O levantamento a partir da Biblioteca Digital de Teses e Dissertações (BDTD), utilizando os termos "anos/séries iniciais" e "Matemática", revelou 57 trabalhos, sendo 45 dissertações e 12 teses, no período de 2004 a 2014. Com base na leitura dos seus títulos, palavras-chave e resumos, destacou-se a pesquisa de Cardoso (2014), que apresenta um estudo sobre o Estado do Conhecimento, a partir de dissertações e teses voltadas à relação entre a formação de professores e a abordagem do sistema de numeração decimal.

Dos 56 trabalhos restantes, 32 deles ( 27 dissertações e 5 teses) referem-se às práticas docentes e aos processos de ensino e aprendizagem da Matemática nos anos iniciais. Nesse conjunto, as discussões apresentadas enfocam: significado do erro; currículo e avaliações externas (Prova Brasil); pedagogia financeira; ensino da Matemática e educação inclusiva; salas de recurso/apoio, relação dos professores de apoio com os professores regentes das turmas e ensino de Matemática para crianças dos anos iniciais que apresentam deficiência; importância das metodologias de ensino, como pesquisa, investigação, resolução de problemas, mídias tecnológicas e utilização de instrumentos e estratégias (jogos, computadores, cálculo mental, representações semióticas, entre outras) no ensino da Matemática; conhecimento didático dos professores sobre os conteúdos matemáticos a serem trabalhados e suas concepções de Matemática e ensino de Matemática.

Os trabalhos analisados constituem uma rica bibliografia sobre a Matemática dos anos iniciais do ensino fundamental, seu ensino e aprendizagem. Entretanto, não tratam diretamente da formação matemática de professores para os anos iniciais, foco da presente reflexão. Portanto, esta análise concentra-se nos 24 trabalhos - 16 dissertações e oito teses -- que o fazem, cujos resultados são apresentados a seguir.

\section{AS PESQUISAS E A FORMAÇÃO MATEMÁTICA DE PROFESSORES PARA OS ANOS INICIAIS}

Realizou-se a análise de conteúdo e a categorização dos trabalhos que abordam a formação de professores para o ensino de Matemática para os anos iniciais do ensino fundamental com base em Bardin (2011), considerando que o pesquisador ao realizar a leitura não a faz à letra, e sim buscando um sentido que se encontra oculto, em segundo plano, "aquilo que está por trás das palavras sobre as quais se debruça" (BARDIN, 2011, p. 50).

Para análise e categorização, além da leitura dos títulos, palavras-chave e resumos, fez-se uma leitura flutuante, buscando identificar objeto de estudo, procedimentos metodológicos e resultados obtidos. Os trabalhos selecionados foram organizados com base em seus objetos de estudo em duas categorias, apresentadas no quadro a seguir. 
Quadro 1. Formação matemática de professores para os anos iniciais do ensino fundamental.

\begin{tabular}{|c|c|c|c|}
\hline Categorias & Teses & Dissertações & Síntese \\
\hline Formação inicial & $\begin{array}{l}\text { Silva (2009) } \\
\text { Ortega (2011) } \\
\text { Bertini (2013) }\end{array}$ & $\begin{array}{l}\text { Mioto (2008) } \\
\text { Araujo (2009) } \\
\text { Giraldelli (2009) } \\
\text { Santos (2009) } \\
\text { Tozetto (2009) } \\
\text { Cunha (2010) } \\
\text { Pinto (2010) } \\
\text { Cordeiro (2011) } \\
\text { Mota (2012) }\end{array}$ & $\begin{array}{l}\text { Trazem reflexões acerca da formação matemática } \\
\text { de professores para os anos iniciais do ensino } \\
\text { fundamental com ênfase nos cursos de Pedagogia. }\end{array}$ \\
\hline Formação continuada & $\begin{array}{l}\text { Purificação (2005) } \\
\text { Alves (2007) } \\
\text { Freire (2011) } \\
\text { Motta (2011) } \\
\text { Lamonato (2012) }\end{array}$ & $\begin{array}{l}\text { Soares (2004) } \\
\text { Maccarini (2007) } \\
\text { Veras (2010) } \\
\text { Silva (2011) } \\
\text { Oliveira (2012) } \\
\text { Rabaiolli (2013) } \\
\text { Santos (2013) }\end{array}$ & $\begin{array}{l}\text { Discutem a oferta de formação continuada } \\
\text { para os professores dos anos iniciais do } \\
\text { ensino fundamental, como oportunidade para } \\
\text { aproximação e domínio dos conhecimentos } \\
\text { matemáticos necessários à docência nesse nível } \\
\text { de ensino e como forma de minorar possíveis } \\
\text { lacunas deixadas pela formação inicial. }\end{array}$ \\
\hline
\end{tabular}

Fonte: Dados coletados pelos autores.

Todos os trabalhos investigam a formação matemática dos professores. Contudo, enquanto as pesquisas que integram a categoria formação inicial investigam-na nos cursos de Formação de Docentes, em nível médio, Pedagogia e Licenciatura em Matemática, os trabalhos classificados na segunda categoria investigam os cursos de formação continuada, assim como os recursos utilizados por professores para atualização profissional. As pesquisas apresentam abordagem qualitativa, predominando estudos de caso, pesquisa-ação e pesquisa de campo, sendo os principais instrumentos de coleta de dados questionários, observação e entrevistas.

\section{Pesquisas Relativas À FORMAÇÃo INICIAL DE PROFESSORES PARA OS ANOS INICIAIS}

A maioria das investigações na categoria formação inicial dos professores dos anos iniciais envolve especificamente os cursos de Pedagogia, e apenas dois dos trabalhos selecionados referem-se à formação inicial em nível médio.

Giraldeli (2009) pesquisou os cursos de formação de professores, em nível médio, e os cursos de Pedagogia e Licenciatura em Matemática, em nível superior. Seus resultados revelam que os três cursos deixam lacunas na formação matemática docente. Enquanto os cursos em nível médio e Pedagogia enfatizam as questões pedagógicas e metodológicas desvinculadas do domínio de conteúdo, o curso de Licenciatura em Matemática privilegia o conhecimento matemático desvinculado da didática, o que dificulta o ensino dessa disciplina principalmente nos anos iniciais. Pinto (2010) ratifica falhas na formação matemática propiciada pelos cursos em nível médio, afirmando que, embora habilitem para o ensino nos anos iniciais, não oferecem uma formação matemática suficiente para a docência.

Silva (2009) investigou o conhecimento matemático de egressos do curso de Pedagogia referente ao campo multiplicativo. Salienta a necessidade de reformulação dos cursos de formação inicial de professores para os anos iniciais e também a necessidade de que a formação profissional ocorra de forma continuada. Tozetto (2009) e Cordeiro (2011) também identificam, entre outros aspectos, lacunas em relação à formação matemática nos cursos de Pedagogia.

Mioto (2008) pesquisou as possibilidades de que alunos do curso de Pedagogia construíssem conceitos matemáticos durante a realização dos estágios supervisionados, tendo, como agente formador, a professora dos anos iniciais. A pesquisa possibilitou verificar que, embora a maioria dos alunos investigados afirmasse não possuir afinidade com a Matemática, além de trazerem lacunas da educação básica, dificultando a formação no curso de Pedagogia, o estágio supervisionado constituiu-se em um momento de formação, contribuindo para superação dessas lacunas e da dicotomia entre teoria e prática.

Algumas pesquisas, como as realizadas por Cunha (2010) e Ortega (2011), investigaram as concepções dos alunos do curso de Pedagogia, sobre a Matemática e seu ensino. Constataram certo receio e concepções negativas trazidos da educação básica. Revelam, ainda, que tanto 
os egressos do curso de Pedagogia quanto os alunos em processo de formação apresentam uma compreensão equivocada ou insuficiente dos conceitos matemáticos e de metodologias adequadas para trabalhar a Matemática nos anos iniciais.

Entretanto, enquanto Cunha (2010) - cuja pesquisa envolveu um curso de Pedagogia de uma instituição pública do Estado de Mato Grosso - considera que a graduação em Pedagogia não contribuiu para a superação de dificuldades e concepções matemáticas equivocadas, Ortega (2011) - que acompanhou os alunos durante os quatro anos de um curso de Pedagogia da Faculdade de Ciências e Tecnologia da Unesp, campus de Presidente Prudente (SP) -, contrapondo-se à constatação de Cunha (2010), verificou que o curso lhes possibilitou ressignificar suas concepções sobre a Matemática. E permitiu-lhes maior segurança em seu ensino nos anos iniciais, ainda que não tivessem completo domínio de alguns conteúdos. $\mathrm{Na}$ busca de identificar diferenças significativas entre os cursos investigados por Cunha (2010) e Ortega (2011), cabe ressaltar as disciplinas que propiciam a formação matemática do pedagogo.

$\mathrm{Na}$ instituição pesquisada por Cunha (2010), a formação matemática ocorre no desenvolvimento de duas disciplinas: Matemática Básica, no segundo semestre do curso, ministrada por professores do Departamento de Matemática, com o objetivo de proporcionar uma apreensão dos conceitos matemáticos; e Matemática para Início da Escolarização, ministrada por professores do Departamento de Pedagogia, objetivando estudar métodos e técnicas de ensino de Matemática para os anos iniciais.

O professor de Matemática Básica, "mesmo observando a dificuldade de aprendizagem e a falta de interesse dos alunos, balizou-se por reproduzir o modelo tradicional de ensino, reforçando o fato de a Matemática ser difícil para os alunos que realizam o curso de Pedagogia" (CUNHA, p. 61). Já o professor de Matemática para Início da Escolarização considera que "a Matemática dos anos iniciais é fácil de ensinar, independentemente do conhecimento do professor". Ou seja, para dar aulas de Matemática, não precisa saber Matemática, basta saber como ensiná-la (CUNHA, 2010 p. 63).

Assim, observa-se na pesquisa desenvolvida por Cunha (2010), que as disciplinas são trabalhadas de forma desarticulada. Se, por um lado, o professor de Matemática Básica desconhece os elementos constituintes da formação integral do pedagogo, apresentando um ensino tradicional; por outro, o professor de Matemática para Início da Escolarização, mesmo identificando a dificuldade conceitual dos alunos, detém-se a trabalhar as metodologias e estratégias de ensino. Os dados obtidos parecem revelar uma desarticulação entre as duas disciplinas, a qual se fosse superada contribuiria para melhor formação discente.

$\mathrm{Na}$ instituição pesquisada por Ortega (2011), duas disciplinas são responsáveis pela formação matemática dos futuros professores dos anos iniciais: Conteúdo, Metodologia e Prática de Ensino de Matemática I e II, abordando conceitos, metodologias e estratégias de ensino. As aulas são ministradas pela mesma professora, licenciada em Matemática, com Mestrado em Educação, e experiência docente na educação básica, "com o objetivo de desmitificar [...] e possibilitar uma compreensão deste conhecimento enquanto construção humana, logo, passível de erros, de revisões" (ORTEGA, 2011, p. 130), propiciando aos alunos a construção e a reconstrução de conceitos matemáticos.

Corroborando com as constatações de Ortega (2011), Mota (2012) analisou o conhecimento de futuros pedagogos sobre as operações aritméticas e identificou receios, além do fato de não gostarem de Matemática. Entretanto, à medida que superavam as dificuldades referentes aos conceitos matemáticos, especificamente às operações aritméticas, ressignificavam suas concepções e sentiam-se mais seguros para ensinar a disciplina.

Ainda na perspectiva da formação inicial, três dos trabalhos selecionados abordaram pesquisas sobre cursos de Pedagogia na modalidade Educação a Distância - EAD. Araujo (2009) e Santos (2009) investigaram a contribuição dos registros dos alunos, na disciplina denominada Representações do Mundo pela Matemática. Constataram que os registros e narrações das aprendizagens discentes levavam à reflexão sobre a ação e à produção ou ressignificação de conceitos, constituindo novas práticas.

Finalmente, Bertini (2013), ao pôr em foco o curso de Pedagogia a distância, propos uma discussão sobre os tutores desses cursos, procurando identificar, em suas práticas nas disciplinas que abordam os conteúdos matemáticos, ações que pudessem identificá-los como formadores de professores. A pesquisa revelou que os tutores exerciam o papel de formadores quando se envolviam não só com a formação dos estudantes, mas também com sua própria formação. A autora ressalta que a qualidade de um curso a distância está ligada tanto à organização da tutoria quanto à condução do trabalho pelo professor da disciplina.

O Quadro 2 sintetiza o resumo das pesquisas analisadas envolvendo a formação inicial de professores para os anos iniciais. 
Quadro 2. Pesquisas sobre a formação inicial de professores para os anos iniciais do ensino fundamental.

\begin{tabular}{|c|c|c|c|c|c|}
\hline Cursos & Dissertações & Teses & Procedimentos & Resultados & Recomendações \\
\hline \multirow{2}{*}{ 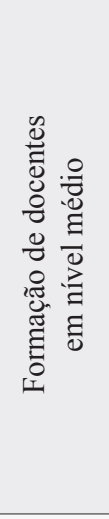 } & Giraldeli (2009) & & $\begin{array}{l}\text { Investigou a formação } \\
\text { matemática de professores } \\
\text { dos anos iniciais, } \\
\text { comparando os cursos: } \\
\text { Formação de Docentes, em } \\
\text { nível médio; Pedagogia } \\
\text { e Licenciatura em } \\
\text { Matemática. }\end{array}$ & $\begin{array}{l}\text { Os três cursos deixam } \\
\text { lacunas na formação } \\
\text { matemática docente. }\end{array}$ & $\begin{array}{l}\text { Articular conhecimentos } \\
\text { de conteúdo matemático, } \\
\text { didático e curricular nesses } \\
\text { cursos de formação inicial. }\end{array}$ \\
\hline & Pinto (2010) & & $\begin{array}{l}\text { Investigou } 27 \text { professoras } \\
\text { da mesma escola com } \\
\text { formação no Curso } \\
\text { Normal - Técnico } \\
\text { Profissionalizante. }\end{array}$ & $\begin{array}{l}\text { As professoras não } \\
\text { dominam os conceitos } \\
\text { aritméticos que ensinam. }\end{array}$ & $\begin{array}{l}\text { Aprofundar os } \\
\text { conhecimentos aritméticos } \\
\text { docentes. }\end{array}$ \\
\hline \multirow{5}{*}{$\begin{array}{l}\frac{\pi}{60} \\
0 \\
00 \\
\frac{\pi}{0} \\
0 \\
0\end{array}$} & Mota (2012) & Silva (2009) & $\begin{array}{l}\text { Verificaram a apropriação } \\
\text { dos conceitos matemáticos } \\
\text { de professores a partir } \\
\text { de um conteúdo pré- } \\
\text { selecionado. }\end{array}$ & $\begin{array}{l}\text { Os cursos deixam lacunas } \\
\text { em relação à formação } \\
\text { matemática docente. } \\
\text { Algumas metodologias } \\
\text { podem contribuir para } \\
\text { superá-las. }\end{array}$ & $\begin{array}{l}\text { Reformular os cursos } \\
\text { de formação inicial e } \\
\text { implementar cursos de } \\
\text { formação continuada. }\end{array}$ \\
\hline & $\begin{array}{l}\text { Tozetto }(2009) \\
\text { Cordeiro }(2011)\end{array}$ & & $\begin{array}{l}\text { Analisaram documentos } \\
\text { dos cursos e observaram } \\
\text { aulas das disciplinas } \\
\text { relativas à formação } \\
\text { matemática. }\end{array}$ & $\begin{array}{l}\text { Os cursos apresentam } \\
\text { lacunas no conhecimento } \\
\text { pedagógico, curricular e } \\
\text { conceitual. }\end{array}$ & $\begin{array}{l}\text { Rever os cursos de } \\
\text { formação inicial. }\end{array}$ \\
\hline & Mioto (2009) & & $\begin{array}{l}\text { Investigou a construção } \\
\text { de conceitos matemáticos } \\
\text { durante o estágio } \\
\text { supervisionado. }\end{array}$ & $\begin{array}{l}\text { O estágio supervisionado } \\
\text { constitui-se em um } \\
\text { momento de formação, } \\
\text { contribuindo para superar } \\
\text { lacunas e a dicotomia entre } \\
\text { teoria e prática. }\end{array}$ & $\begin{array}{l}\text { Organizar o estágio } \\
\text { supervisionado, } \\
\text { possibilitando a } \\
\text { apropriação de } \\
\text { conceitos matemáticos e } \\
\text { metodologias de ensino. }\end{array}$ \\
\hline & $\begin{array}{l}\text { Cunha (2010) } \\
\text { Mota (2012) }\end{array}$ & Ortega (2011) & $\begin{array}{l}\text { Investigaram as } \\
\text { concepções sobre a } \\
\text { Matemática de alunos de } \\
\text { graduação. }\end{array}$ & $\begin{array}{l}\text { Conceitos e metodologias } \\
\text { equivocados. Apropriação } \\
\text { dos conhecimentos } \\
\text { matemáticos contribui para } \\
\text { ressignificar concepções } \\
\text { sobre a Matemática. }\end{array}$ & $\begin{array}{l}\text { Possibilitar a apropriação } \\
\text { dos conhecimentos } \\
\text { matemáticos na formação } \\
\text { inicial e continuada. }\end{array}$ \\
\hline & $\begin{array}{l}\text { Araújo (2009) } \\
\text { Santos (2009) }\end{array}$ & Bertini (2013) & $\begin{array}{l}\text { Investigaram a formação } \\
\text { de docentes no curso } \\
\text { superior de Pedagogia, na } \\
\text { modalidade a distância. }\end{array}$ & $\begin{array}{l}\text { O registro das } \\
\text { aprendizagens possibilita } \\
\text { novos conhecimentos, } \\
\text { constituindo novas } \\
\text { concepções e práticas. }\end{array}$ & $\begin{array}{l}\text { Refletir sobre a prática para } \\
\text { transformá-la. Valorizar } \\
\text { e organizar a tutoria na } \\
\text { formação matemática. } \\
\text { Necessidade de formação } \\
\text { continuada. }\end{array}$ \\
\hline
\end{tabular}

Fonte: Dados coletados pelos autores.

\section{PESQuisas RELATIVAS À FORMAÇÃo CONTINUADA DE PROFESSORES PARA OS ANOS INICIAIS}

Os trabalhos desta segunda categoria destacam a insuficiência da formação inicial, uma vez que tanto os professores quanto os futuros professores apresentam dificuldades em relação ao domínio de conceitos e metodologias para o ensino de Matemática nos anos iniciais, e indicam cursos e grupos de estudos como possibilidade para a superação de tais dificuldades (PURIFICAÇÃO, 2005; RABAIOLLI, 2013; SILVA, 2011; FREIRE, 2011).

As pesquisas ressaltam, ainda, a necessidade de os professores/docentes nos cursos de formação continuada utilizarem metodologias e instrumentos que favoreçam a compreensão dos conceitos matemáticos, contribuindo para a formação pedagógica dos docentes/alunos. A 
História da Matemática (SOARES, 2004) e a Resolução de Problemas (OLIVEIRA, 2012) podem orientar o trabalho docente e contribuir para a compreensão dos conceitos matemáticos. Mas é necessário que o professor dos anos iniciais aproprie-se dessas metodologias - o que pode acontecer por meio da formação continuada -e as utilize.

A Investigação Matemática representa outro encaminhamento metodológico e consiste na exploração das diferentes formas de resolução de problemas abertos, possibilitando ao aluno levantar hipóteses, confirmálas ou refutá-las na busca das soluções (PARANÁ, 2008). Pesquisas realizadas avaliando a relevância dessa abordagem (LAMONATO, 2012) ou a organização de "cenários para investigação" (RABAIOLLI, 2013) constataram que, além de favorecerem a ampliação do conhecimento sobre Geometria (conteúdo abordado na formação), os professores refletiram sobre a prática docente e passaram a considerar a possibilidade de utilizarem atividades investigativas em suas aulas.

Outra perspectiva de análise, ainda dentro da categoria formação continuada, envolve a construção ou reformulação do currículo. Motta (2011) e Santos (2013), ao investigarem formações promovidas nas escolas, verificaram que esses momentos, além de possibilitarem a construção/reformulação do currículo, possibilitam também aos professores aprofundamento dos conhecimentos matemáticos e a reflexão sobre a prática pedagógica.

A análise de investigações, nas quais os pesquisadores acompanharam professores participantes de grupos de formação em Matemática, revela mudanças em suas práticas docentes. É relevante destacar sua importância e seus bons resultados.

As pesquisas de Purificação (2005), Alves (2007), Veras (2010) e Oliveira (2012) envolveram professores de Matemática nos anos iniciais em grupos de estudo colaborativos e concluíram que esses trabalhos ampliaram o acesso a conhecimentos específicos. Além de possibilitarem a reconstrução de conceitos e a reelaboração de saberes, e promoverem a reflexão sobre a prática docente, possibilitando a implantação de atividades mais significativas em suas aulas.

Diante dos resultados de todas as pesquisas analisadas, ficam claras a importância e a necessidade de atividades de formação continuada que abordem conhecimentos matemáticos. Maccarini (2007, p. 11) resume essa relevância manifestada no discurso dos professores que participaram de sua pesquisa: "[...] o aprofundamento dos conteúdos matemáticos, as abordagens metodológicas e a utilização de novos recursos e técnicas de ensino, possibilitados na formação continuada, contribuem para a melhoria da prática docente nos anos iniciais". O Quadro 3 apresenta uma síntese das pesquisas analisadas.

Quadro 3. Formação continuada de professores dos anos iniciais

\begin{tabular}{|c|c|c|c|c|}
\hline Dissertações & Teses & Procedimentos & Resultados & Recomendações \\
\hline $\begin{array}{l}\text { Soares (2004) } \\
\text { Maccarini (2007) } \\
\text { Rabaiolli (2013) }\end{array}$ & $\begin{array}{l}\text { Oliveira (2012) } \\
\text { Lamonato (2012) }\end{array}$ & $\begin{array}{l}\text { Investigaram a formação e a } \\
\text { utilização de metodologias } \\
\text { em educação matemática de } \\
\text { docentes frequentando cursos } \\
\text { de formação continuada. }\end{array}$ & $\begin{array}{l}\text { Lacunas na formação. } \\
\text { Utilização da História da } \\
\text { Matemática, Investigação } \\
\text { e Resolução de Problemas } \\
\text { contribui para a formação } \\
\text { matemática do docente e do } \\
\text { discente dos anos iniciais. }\end{array}$ & $\begin{array}{l}\text { Conhecer essas metodologias } \\
\text { na formação continuada } \\
\text { possibilita ao docente/aluno } \\
\text { utilizá-las em sua prática. }\end{array}$ \\
\hline Santos (2013) & Motta (2011) & $\begin{array}{l}\text { Investigaram a formação } \\
\text { continuada durante a } \\
\text { reformulação curricular } \\
\text { nos anos iniciais do ensino } \\
\text { fundamental. }\end{array}$ & $\begin{array}{l}\text { Lacunas na formação. } \\
\text { O estudo dos currículos } \\
\text { possibilitou a apropriação de } \\
\text { conhecimentos matemáticos e } \\
\text { didáticos. }\end{array}$ & $\begin{array}{l}\text { Organizar sistemática e } \\
\text { continuamente estudos para } \\
\text { superação dessas lacunas. }\end{array}$ \\
\hline Veras (2010) & $\begin{array}{l}\text { Purificação (2005) } \\
\text { Alves (2007) } \\
\text { Oliveira (2012) }\end{array}$ & $\begin{array}{l}\text { Investigaram a possibilidade } \\
\text { de organização de formação } \\
\text { continuada por meio de } \\
\text { grupos colaborativos. }\end{array}$ & $\begin{array}{l}\text { Lacunas na formação } \\
\text { matemática dos docentes. } \\
\text { Construção de conceitos } \\
\text { matemáticos e apropriação } \\
\text { dos conhecimentos didáticos } \\
\text { por meio dos grupos } \\
\text { colaborativos. }\end{array}$ & $\begin{array}{l}\text { Organizar grupos } \\
\text { colaborativos, envolvendo } \\
\text { docentes e pesquisadores, na } \\
\text { formação continuada. }\end{array}$ \\
\hline Silva (2011) & $\begin{array}{l}\text { Purificação (2005) } \\
\text { Freire (2011) }\end{array}$ & $\begin{array}{l}\text { Investigaram a utilização } \\
\text { de materiais manipulativos } \\
\text { e digitais (softwares) na } \\
\text { formação de professores. }\end{array}$ & $\begin{array}{l}\text { Lacunas na formação } \\
\text { matemática dos docentes. } \\
\text { Materiais manipulativos } \\
\text { contribuem para a } \\
\text { apropriação dos conceitos. }\end{array}$ & $\begin{array}{l}\text { Utilizar materiais } \\
\text { manipulativos e softwares } \\
\text { matemáticos para formação } \\
\text { continuada. }\end{array}$ \\
\hline
\end{tabular}

Fonte: dados coletados pelos autores. 


\section{CONSIDERAÇÕES, MAS NÃO FINAIS}

A apropriação dos conhecimentos científicos é essencial para o desenvolvimento das funções psicológicas superiores e cabe à escola, como compromisso primeiro, transmiti-los de forma que os alunos deles se apropriem. Entretanto, constata-se, nas pesquisas relatadas, que os professores dos anos iniciais apresentam lacunas em sua formação matemática, dificultando a muitos de seus alunos a apropriação dos conceitos matemáticos.

As pesquisas revelam, também, que o processo de formação docente tem negado a esses professores, ainda quando alunos da educação básica ou superior, o direito à apropriação dos conhecimentos científicos. Assim, como desenvolverão atividades de mediação adequadas no processo de ensino e aprendizagem? Como poderão ensinar o que não aprenderam?

É importante destacar a preocupação dos pesquisadores quanto à formação matemática para a docência nos anos iniciais do ensino fundamental. Entretanto essa formação está articulada a todos os níveis de ensino, e cada qual é responsável por sua parte, na busca de superar os problemas relativos à apropriação dos conhecimentos matemáticos por parte dos professores e futuros professores.

As pesquisas que analisam os cursos de Pedagogia, as principais responsáveis pela graduação dos professores dos anos iniciais, foram realizadas a partir de 2009, ou seja, investigaram essa formação já nos moldes das Diretrizes Nacionais (2006) e apontam lacunas, tanto na apropriação de conceitos matemáticos quanto de metodologias para o ensino dessa disciplina. Ou seja, mesmo sendo um momento importante na articulação dos conhecimentos necessários à prática educativa, tal formação apresentase insuficiente no que se refere à Matemática, uma vez que o tempo destinado à apropriação dos fundamentos e conceitos matemáticos é bastante restrito.

A formação inicial tem se revelado insuficiente, entretanto, dificilmente, um curso poderá abarcar todos os conhecimentos necessários à atuação profissional, ainda mais se for considerada a gama de atividades profissionais permitidas legalmente ao pedagogo. $\mathrm{Na}$ perspectiva de superar as lacunas deixadas pela formação inicial, com relação aos conhecimentos matemáticos necessários à docência nos primeiros anos da educação básica, as pesquisas são unânimes em apontar a importância da formação continuada.

Muitas ações realizadas no interior da escola contribuem para a contínua formação docente, a qual não ocorre necessariamente por meio de cursos. Uma das ações destacadas nas pesquisas, por seus resultados positivos, são os grupos organizados na perspectiva do trabalho colaborativo. Ressalta-se, ainda, a relevância do estudo sobre a concepção e utilização de metodologias como Resolução de Problemas, História da Matemática ou Investigação Matemática. indicadas, tanto como encaminhamentos metodológicos para a formação continuada quanto como tema de estudo nesses momentos de formação.

$\mathrm{Se}$, por um lado, essas metodologias podem favorecer a apropriação dos conceitos matemáticos por parte dos professores por outro, é importante que os docentes delas se apropriem buscando inovar e melhorar a qualidade do ensino e, consequentemente, da aprendizagem da Matemática. Para isso, talvez seja necessário um suporte pedagógico contínuo a fim de que o professor sinta-se seguro para utilizar novas estratégias didáticas.

A complexidade dos conhecimentos científicos atualmente é tão grande que sua apreensão nunca se esgota. Mas, quando se trata do ensino fundamental, está-se referindo aos conhecimentos básicos que qualquer cidadão pode se apropriar e que são necessários à vivência cotidiana. Portanto, há necessidade de se empreenderem pesquisas com o intuito de expandir as discussões sobre a formação inicial e continuada de professores dos anos iniciais, buscando possibilidades de superação das dificuldades relatadas. Objetivam-se as mudanças evidentemente necessárias, que visam a contribuir para a melhoria da qualidade do ensino na educação básica.

Nesse sentido, políticas públicas que promovam a aprendizagem na educação básica, tais como a implantação de salas de apoio ou de reforço, podem contribuir para que os alunos/docentes cheguem à universidade tendo se apropriado dos conhecimentos matemáticos fundamentais, cabendo aos cursos de Pedagogia trabalhar a questão metodológica. Políticas públicas que promovam a formação continuada, propiciando condições para grupos de estudo, cursos envolvendo o acompanhamento docente em sala de aula, cursos de longa duração, como o Programa de Desenvolvimento Educacional (PDE) promovido pelo estado do Paraná, ampliando a formação docente, são fundamentais para a efetivação do processo de ensino-aprendizagem.

\section{REFERÊNCIAS}

BARDIN, L. Análise de conteúdo. São Paulo: Edições 70, 2011. BRASIL. Diretrizes Curriculares Nacionais Gerais da Educação Básica. Brasília, DF: MEC, SEB, Dicei, 2013.

. Lei no 9.394, de 20 de dezembro de 1996. Lei de Diretrizes e Bases da Educação Nacional. Brasília, DF: MEC, 1996.

Ministério da Educação. Conselho Nacional da Educação. Resolução CNE/CP no 1/2002, de 18 de fevereiro de 2002. Institui Diretrizes Curriculares Nacionais para a Formação de Professores da Educação Básica, em nível superior, curso de licenciatura, de graduação plena. Diário Oficial da União, Brasília, 9 de abril de 2002. Seção 1, p. 31. 
Ministério da Educação. Conselho Nacional da Educação. Resolução CNE/CP no 1/2006, de 15 de maio de 2006. Institui Diretrizes Curriculares Nacionais para o Curso de Graduação em Pedagogia, licenciatura. Diário Oficial da União, Brasília, 16 de maio de 2006. Seção 1, p.11.

CURI, E. Formação de professores de Matemática: realidade presente e perspectivas futuras. Dissertação (Mestrado) BDTD, 2000. Disponível em: <http://bdtd.ibict.br/>. Acesso em: 10 jul. 2014.

FROTA, M. C. R. Concepções de Matemática e aprendizagem matemática de alunos de Engenharia. Anais da Anped, GT 19, 2003.

LOPES, A. R. L. V. et al. Professoras que ensinam Matemática nos anos iniciais e sua formação. Linhas Críticas, v. 18, n. 35, p. 87-106, 2012.

MARMITT, V. R. Concepções e atitudes em relação à Matemática: maneiras de identificá-las e possibilidades de modificá-las. Dissertação (Mestrado) - BDTD, 2009. Disponível em: <http://bdtd.ibict.br/>. Acesso em: 10 jul. 2014.

MARTINS, L. M. O desenvolvimento do psiquismo e a educação escolar: contribuições à luz da Psicologia HistóricoCultural para a Pedagogia Histórico-Crítica. São Paulo: Autores Associados, 2013.

NACARATO, A. M.; MENGALI, B. L. S.; PASSOS, C. L. B. A Matemática nos anos iniciais do Ensino Fundamental: tecendo fios do ensinar e do aprender. Belo Horizonte: Autêntica, 2009.

PARANÁ. Secretaria de Estado da Educação - Seed. Diretrizes Curriculares da Rede Pública da Educação Básica do Estado do Paraná (DCE): Matemática, Curitiba, 2008.

SILVEIRA, M. R. A. "Matemática é difícil": um sentido préconstruído evidenciado na fala dos alunos. Anais da Anped, GT 19, 2002.

ZAT, A. D. A formação docente e as crenças de professores em relação à Matemática: uma ruptura possível? Tese (Doutorado) - BDTD, 2012. Disponível em: <http://bdtd.ibict. br/>. Acesso em: 10 jul. 2014.

\section{DisSERTAÇÕES E TESES ANALISADAS}

ALVES, F. T. O. Quando as professoras se encontram para estudar Matemática: saberes em movimento. Tese (Doutorado) - Universidade Federal do Rio Grande do Norte/ UFRN, Natal, 2007.

ARAUJO, A. R. de. Práticas pedagógicas em transformação: contribuições da interdisciplinar na representação do mundo pela Matemática no Curso de Pedagogia a Distância da Universidade Federal do Rio Grande do Sul. 103 p. Dissertação (Mestrado) - Universidade Federal do Rio Grande do Sul, UFRGS, Porto Alegre, 2009.

BERTINI, L. de F. O tutor virtual como formador: a Matemática no curso de Pedagogia a distância da UFSCar. 231 p. Tese (Doutorado) - Universidade Federal de São Carlos, UFSCar, São Carlos, 2013.

CORDEIRO, R. M. A. Análise do processo de formação de professores para o ensino de Matemática nos anos iniciais. Dissertação (Mestrado) - Universidade Federal Rural de Pernambuco, Recife, 2011.
CUNHA, D. R. A Matemática na formação de professores dos anos iniciais do Ensino Fundamental: relações entre a formação inicial e a prática pedagógica. 107 p. Dissertação (Mestrado) - Faculdade de Física, Pontifícia Universidade Católica do Rio Grande do Sul, PUCRS, Porto Alegre, 2010.

FREIRE, R. S. Desenvolvimento de conceitos algébricos por professores dos anos iniciais do Ensino Fundamental. 180 p. Tese (Doutorado) - Universidade Federal do Ceará, Fortaleza, 2011

GIRALDELI, M. S. de C. Os diferentes níveis de formação para o ensino de Matemática: concepções e práticas de docentes que atuam nos anos iniciais do Ensino Fundamental. 226 p. Dissertação (Mestrado) - Universidade Católica Dom Bosco, Campo Grande, 2009.

LAMONATO, M. A exploração-investigação Matemática: potencialidades na formação contínua de professores. $250 \mathrm{p}$. Tese (Doutorado) - Universidade Federal de São Carlos, UFSCar, São Carlos, 2012.

MACCARINI, J. I. C. M. Contribuições da formação continuada em Educação Matemática à prática do professor. 215 p. Dissertação (Mestrado) - Universidade Tuiuti do Paraná, Curitiba, 2007.

MIOTO, R. As inter-relações entre universidade e escola básica: o estágio e a prática de futuros professores das séries iniciais na construção de conhecimentos pedagógicos da Matemática. 137 p. Dissertação (Mestrado profissional) - Pontifícia Universidade Católica de São Paulo, PUC-SP, São Paulo, 2008.

MOTA, A. P. A. Operações aritméticas: dificuldades indicadas pelas futuras professoras. $80 \mathrm{p}$. Dissertação (Mestrado) Pontifícia Universidade Católica de Campinas, PUC-Campinas, Campinas, 2012.

MOTTA, C. D. V. B. Um retrato de aprendizagem em Educação Matemática: professoras dos anos iniciais do Ensino Fundamental em processo de inovação curricular. 332 p. Tese (Doutorado) - Faculdade de Educação, Universidade de São Paulo, São Paulo, 2011.

OLIVEIRA, S. A. de. Resolução de problemas na formação continuada e em aulas de Matemática nos anos iniciais. 171 p. Dissertação (Mestrado) - Universidade Federal de São Carlos, UFSCar, São Carlos, 2012.

ORTEGA, E. M. V. A construção dos saberes dos estudantes de Pedagogia em relação à Matemática e seu ensino no decorrer da formação inicial. 164 p. Tese (Doutorado) Faculdade de Educação da Universidade de São Paulo, São Paulo, 2011.

PINTO, V. L. L. de S. Formação Matemática de professores dos anos iniciais do Ensino Fundamental e suas compreensões. 174 p. Dissertação (Mestrado) - Universidade do Grande Rio, Duque de Caxias, 2010.

PURIFICAÇÃO, I. C. da. Cabri-geometre na formação continuada de professores das séries iniciais do Ensino Fundamental: possibilidades e limites. Tese (Doutorado) Pontifícia Universidade Católica de São Paulo, /PUCSP, São Paulo, 2005.

RABAIOLLI, L. L. Geometria nos anos iniciais: uma proposta de formação de professores em cenários para a investigação. Dissertação (Mestrado) - Centro Universitário/Univates, Lajeado, 2013. 
SANTOS, S. A. Experiências narradas no ciberespaço: um olhar para as formas de se pensar e ser professora que ensina Matemática. 123 p. Dissertação (Mestrado) - Universidade Federal do Rio Grande do Sul/UFRGS, Porto Alegre, 2009.

SANTOS, A. G. U. Não é que eu sei ser professora! Formação continuada e construção do currículo da Matemática para o ciclo de alfabetização. 139 p. Dissertação (Mestrado) - Universidade Federal do Rio Grande do Norte/UFRN, Natal, 2013.

SILVA, A. C. da. A constituição dos saberes da docência: uma análise do campo multiplicativo. Tese (Doutorado) - Pontifícia Universidade Católica de São Paulo/PUCSP, São Paulo, 2009.

SILVA, J. B. R. da. Formação continuada de professores que ensinam Matemática: o papel do ábaco na ressignificação da prática pedagógica. 178 p. Dissertação (Mestrado) - Universidade Federal do Rio Grande do Norte/UFRN, Natal, 2011.
SOARES, K. M. História da Matemática na formação de professores do Ensino Fundamental - (1ํa a $4^{\mathrm{a}}$ série). 132 p. Dissertação (Mestrado) - Universidade do Estado de Santa Catarina/UDSC, Florianópolis, 2004.

TOZETTO, A. S. Letramento para a docência em Matemática nos anos iniciais do Ensino Fundamental. 161 p. Dissertação (Mestrado) - Universidade Estadual de Ponta Grossa, Ponta Grossa, 2010.

VERAS, C. M. A Estatística nas séries iniciais: uma experiência de formação com um grupo colaborativo com professores polivalentes. 136 p. Dissertação (Mestrado Profissional) - Pontifícia Universidade Católica de São Paulo, PUCSP, São Paulo, 2010.

Recebido em 20-11-2015.

Aprovado em 05-08-2016. 